\title{
Comparative Study on the Characteristics of Sporting Goods Consumption Behavior of Chinese College Students
}

\author{
Lihua Yu \& Eung-Soo Oh
}

Dong-A University, South Korea

\begin{abstract}
College students are the main group of sports consumption in the future. Therefore, it is very important to understand the motivation of college students' sporting goods consumption and evaluate the importance and satisfaction of college students' purchase behavior of sporting goods. Currently, there are mainly three evaluation methods based on satisfaction, sUch as SERVQUAL model (service quality) proposed by Parasuraman A in 1985, the SERVPERF model (service performance) proposed by Cronin and Taylor in 1992, and the IPA (Important Performance Analysis) proposed by Martilla and James (1977).
\end{abstract}

Keywords: sporting goods, consumption, important performance analysis (IPA), Chinese college students

\section{Article History}

Received 13 September 2020

Accepted 11 September 2020

Published 31 January 2021

Available online 19 February 202

https://doi.org/10.47544/johsk.2021.2.1.38

Corresponding Author
Lihua Yu
yhfish2018@gmail.com
Department of Physical Education
College of Sport Science
Dong-A University, Busan, South Korea

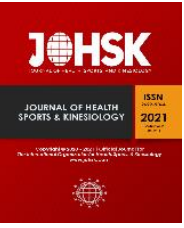

\section{Methods}

The IPA method used matrix coordinates to identify the important factors considered by consumers and the degree of consumer satisfaction with these factors, forming four quadrants of superiority, maintenance, improvement, and disadvantaged areas, thereby judging the elements that should be concentrated and prioritized for improvement. IPA analysis is widely used in many fields such as in tourism (Duke \& Persia, 1996; Deng, 2007; Hudson et al., 2004; Oh, 2001; Wade \& Eagles, 2003), in education (Alberty \& Mihalik, 1989; Ortinau et al., 1989), in sports services (Kwon \& Chung, 2018; Antonio Rial et al., 2008; Erjuan \& Bingshu, 2016; Meng, 2018). Therefore, this article used the IPA analysis method to study 386 Chinese college students who participated in the consumption of sporting goods. The data were analyzed by frequency analysis, exploratory factor analysis, reliability analysis and ImportancePerformance Analysis using SPSS.

\section{Results}

The results of this study were as follows. First, the motivation of college students' sports goods consumption is divided into three dimensions such as conspicuousness, practicality, and individuality. Among them, the conspicuous factor is related to student age, grade, monthly allowance, and brand awareness. Second, the pre-consumption importance and post-consumption satisfaction are divided into six dimensions such as environment, function, price, after-sales, design, and brand. Among the important dimensions considered before consumption, female believe

\section{Journal of Health, Sports, \& Kinesiology | ISSN 2692-9864 | www.johsk.com}


| 2021 | Volume 2 | Issue 1 | The Journal of Health, Sports, and Kinesiology |

that the consumption environment and product functions are more important than male. Compared with nonsports students, sports majors think brand is more important than normal brand. In terms of domestic and foreign brand recognition, LiNing and Nike are considered the most wanted brands. In the post-consumption satisfaction dimension, students are more satisfied with the environment, function, and brand. Third, pre-consumption importance and post-consumption satisfaction are statistically significant difference $(p=0.000)$.

\section{Conclusion}

The IPA analysis showed that marketers should continue to maintain their product design advantages and focus on improving the convenience of after-sales service and consumer environmental sanitation conditions to better meet the needs of different college students.

(c) 2021. This work is licensed under a CC BY-NC-SA 4.0 International license.

This is an open access article distributed under the Creative Commons Attribution License which permits unrestricted use, distribution, and reproduction in any medium, provided the original work is properly cited.

\section{Journal of Health, Sports, \& Kinesiology | ISSN 2692-9864 | www.johsk.com}

